\title{
Reactions of Trimethylsilylated Silicate Anions in Acidic Media. Part 2.† The Influence of Reaction Parameters
}

\author{
(The late) Gabriella Garzó, Dagobert Hoebbel, Anna Vargha, " and Kálmán Ujszászi \\ Research Laboratory for Inorganic Chemistry. Hungarian Academy of Sciences, 1112 Budapest, \\ Budaörsi út 45, Hungary
}

\begin{abstract}
It is shown that the ion-exchange resin Amberlyst 15 acts as a powerful proton donor for SiO bond cleavages and rearrangements of trimethylsiloxysiloxanes. In the presence of hexamethyldisiloxane, transformations of trimethylsiloxysiloxanes of different structure show a dual effect: highly caged structures are loosened, while very loose structures become more rigid. Tetrameric ring structures predominate in the reaction products. The transformation reactions are controlled by the acid to hexamethyldisiloxane ratio in the reaction mixture. In the absence of hexamethyldisiloxane trimethylsiloxysiloxanes are highly degraded.
\end{abstract}

Trimethylsilylation followed by gas chromatographic (g.c.) and mass spectrometric (m.s.) investigations is a valuable method for the identification of various silicate anions. However, structural changes in the original silicate anions occurring during the derivatization cannot be completely excluded. Extensive studies by several authors ${ }^{1-9}$ have been directed towards minimizing such side reactions.

While practically all investigations have used subsequent treatment of the silylation product with an acidic ion-exchange resin (Amberlyst 15) in hexamethyldisiloxane solution for completing the trimethylsilylation, only Calhoun and Masson ${ }^{4}$ and ourselves ${ }^{8,10}$ have observed the interconversion of siloxane structures caused by the Amberlyst 15 .

Part 1 of this Series ${ }^{10}$ described proton-catalysed chemical and structural transformations of the trimethylsilylated silicates $\mathrm{Si}_{6} \mathrm{O}_{15}\left(\mathrm{SiMe}_{3}\right)_{6}$ (a triangular prism) and $\mathrm{Si}_{6} \mathrm{O}_{18}\left(\mathrm{SiMe}_{3}\right)_{12}$ (a hexameric ring) in the presence of hexamethyldisiloxane. The aim of that work was to show that the protonated form of Amberlyst 15 ion-exchange resin acted as a powerful acid in these transformations. The results provided strong evidence for a substantial contribution of the Amberlyst treatment to side reactions, resulting in the formation of siloxane structures not present in the original silicate.

Three main types of the trimethylsilylated silicate transformations were outlined in Part 1: (i) decrease in the condensation degree of the molecular structure via cleavage of one skeletal $\equiv \mathrm{Si}-\mathrm{O}-\mathrm{Si} \equiv$ bond followed by trimethylsilylation; (ii) increase in the condensation degree of the molecular structure by cleavage of two substituent $\equiv \mathrm{Si}-\mathrm{O}-\mathrm{Si} \equiv$ bonds followed by the formation of a new skeletal $=\mathrm{Si}-\mathrm{O}-\mathrm{Si} \equiv$ bond; and (iii) isomerization via intramolecular rearrangement; most probably the cleavage of one skeletal and one substituent $\equiv \mathrm{Si}-\mathrm{O}-\mathrm{Si} \equiv$ bond followed by siloxane bond rearrangement and $\mathrm{OSiMe}_{3}$ group migration. It was also shown that the acidic transformations of the hexameric trimethylsiloxanes $\mathrm{Si}_{6} \mathrm{O}_{15}\left(\mathrm{SiMe}_{3}\right)_{6}$ and $\mathrm{Si}_{6} \mathrm{O}_{18}\left(\mathrm{SiMe}_{3}\right)_{12}$ tend to produce structures containing only tetrameric siloxane rings starting from cyclic and polycyclic silicate derivatives containing trimeric (pentameric) or hexameric siloxane rings.

In this paper we attempt to give a more fundamental interpretation of trimethylsiloxysiloxane transformations caused by acidic treatment. Therefore, (1) the influence of reaction parameters, such as the type of proton source, the proton concentration, and the solvent composition (hexamethyldisiloxane to heptane ratio), is described and (2) the available information is extended by studies of transformations of a linear tetrameric, $\mathrm{Si}_{4} \mathrm{O}_{13}\left(\mathrm{SiMe}_{3}\right)_{10}$, an octameric, $\mathrm{Si}_{8} \mathrm{O}_{20}\left(\mathrm{SiMe}_{3}\right)_{8}$ (a cube), and a cyclotetrameric, $\mathrm{Si}_{4} \mathrm{O}_{12^{-}}$

† Part 1 is ref. 10.
$\left(\mathrm{SiMe}_{3}\right)_{8}$, trimethylsiloxysiloxane under the influence of Amberlyst 15.

The trimethylsiloxysiloxanes (trimethylsilylated silicates) will be referred to as $\mathrm{QL}$ siloxanes throughout, where $\mathrm{Q}=$ $\mathrm{Si}\left(\mathrm{O}_{0.5}\right)_{4}=\mathrm{SiO}_{2}$ and $\mathrm{L}=\mathrm{O}_{0.5} \mathrm{SiMe}_{3}$.

\section{Experimental}

Materials.-Commercial grade Amberlyst 15 ion-exchange resin (Serva Feinbiochemica $\mathrm{GmBH}$ ) was dried at $80^{\circ} \mathrm{C}$ for $4 \mathrm{~h}$ and checked for activity before use as described previously. ${ }^{10}$ Acid treatments were performed as before. ${ }^{10}$

Preparation of the $\mathrm{QL}$ Oligomers.-The compound $\mathrm{Q}_{6} \mathrm{~L}_{6}$ was prepared from crystalline tetraethylammonium silicate, $\left(\mathrm{NEt}_{4}\right)_{6} \mathrm{Si}_{6} \mathrm{O}_{15} \cdot 57 \mathrm{H}_{2} \mathrm{O}$, by trimethylsilylation; ${ }^{11} \mathrm{Q}_{6} \mathrm{~L}_{12}$ (III) was similarly prepared ${ }^{10}$ from dioptase, $\mathrm{Cu}_{6} \mathrm{Si}_{6} \mathrm{O}_{18} \cdot 6 \mathrm{H}_{2} \mathrm{O}$. A detailed description of the preparation of $\mathrm{Q}_{8} \mathrm{~L}_{8}$ by the trimethylsilylation of crystalline tetramethylammonium silicate, $\left(\mathrm{NMe}_{4}\right)_{8} \mathrm{Si}_{8} \mathrm{O}_{20} \cdot 69 \mathrm{H}_{2} \mathrm{O}$, has been published elsewhere. ${ }^{12}$ The compounds $\mathrm{Q}_{4} \mathrm{~L}_{10}$ and $\mathrm{Q}_{4} \mathrm{~L}_{8}$ were prepared from $\mathrm{Ag}_{10} \mathrm{Si}_{4} \mathrm{O}_{13}$ (kindly supplied by $M$. Jansen, Giessen) and $\mathrm{K}_{4} \mathrm{H}_{4} \mathrm{Si}_{4} \mathrm{O}_{12}$ respectively by trimethylsilylation according to the procedure of Tamás et al., ${ }^{6}$ modified by the omission of the treatment with Amberlyst 15.

Gas Chromatography.-Pyrex glass capillary columns $(25 \mathrm{~m} \times 0.25 \mathrm{~mm}$, coated with OV-101) were used for the analysis of the reaction mixtures. Operating conditions were as previously described. ${ }^{10}$ Siloxane losses during trimethylsilylation were estimated using the 'internal-standard' method for the quantitative evaluation of the chromatograms: ntetradecane served as the internal standard.

Mass Spectrometry.-Mass spectrometric measurements were performed on a AEI MS-902 instrument at $70 \mathrm{eV}$ (ca. $1.12 \times 10^{-17} \mathrm{~J}$ ) ionizing energy. The temperature of the ion source was $180^{\circ} \mathrm{C}$. Samples were introduced directly into the ion source from a quartz probe, the temperature of which could not be adjusted independently of the ion source.

Acid Treatment of QL Siloxanes.-The experimental conditions under which transformations were carried out were as given in Part $1 .{ }^{10}$ For experimental parameters see below.

\section{Results and Discussion}

The separation, characterization, and estimation of the various QL species was undertaken by gas chromatography (g.c.) and mass spectrometry (m.s.) as described previously. ${ }^{10}$ 
Table 1. Main reaction products of trimethylsiloxysiloxanes of different structures in acidic media

\begin{tabular}{|c|c|c|c|c|c|}
\hline Short formula & Schematic structure & $\begin{array}{l}\text { Transformation } \\
\text { product of }\end{array}$ & Short formula & Schematic structure & $\begin{array}{l}\text { Transformation } \\
\text { product of }\end{array}$ \\
\hline$Q_{6} L_{6}$ & & Starting compound & $\mathrm{Q}_{2} \mathrm{~L}_{6}$ & $\mathrm{~L}_{3} \mathrm{Q}-\mathrm{QL}_{3}$ & $Q_{6} L_{6}$ \\
\hline $\mathrm{Q}_{6} \mathrm{~L}_{\mathbf{a}}$ & & $\mathrm{Q}_{6} \mathrm{~L}_{6}$ & $\mathrm{QL}_{4}$ & & $\mathrm{Q}_{6} \mathrm{~L}_{6}, \mathrm{Q}_{6} \mathrm{~L}_{12}$ (III) \\
\hline$Q_{6} L_{10}(I)$ & & $Q_{6} L_{6}, Q_{6} L_{12}$ (III) & $\mathrm{Q}_{8} \mathrm{~L}_{8}$ & & Starting compound \\
\hline (II) & & $\mathrm{Q}_{6} \mathrm{~L}_{6}, \mathrm{Q}_{6} \mathrm{~L}_{12}$ (III) & $\mathrm{Q}_{8} \mathrm{~L}_{10}$ & & $\mathrm{Q}_{8} \mathrm{~L}_{8}$ \\
\hline $\mathrm{Q}_{6} \mathrm{~L}_{12}(\mathrm{I})$ & $\mathrm{L}_{3} \mathrm{O}+$ is & $\mathrm{Q}_{6} \mathrm{~L}_{6}, \mathrm{Q}_{6} \mathrm{~L}_{12}$ (III) & $\mathrm{Q}_{\mathrm{a}} \mathrm{L}_{12}$ & & $\mathrm{Q}_{8} \mathrm{~L}_{\mathbf{8}}$ \\
\hline (II) & & $\mathrm{Q}_{6} \mathrm{~L}_{6}, \mathrm{Q}_{6} \mathrm{~L}_{12}$ (III) & $Q_{4} L_{10}$ & & Starting compound \\
\hline (III) & $\mathrm{L}_{2} \mathrm{O}^{-}$ & Starting compound & $Q_{4} L_{8}$ & & $Q_{4} L_{10}$ \\
\hline
\end{tabular}

Table 2. Experimental parameters of the trimethylsiloxysiloxane transformations in the case of Amberlyst 15

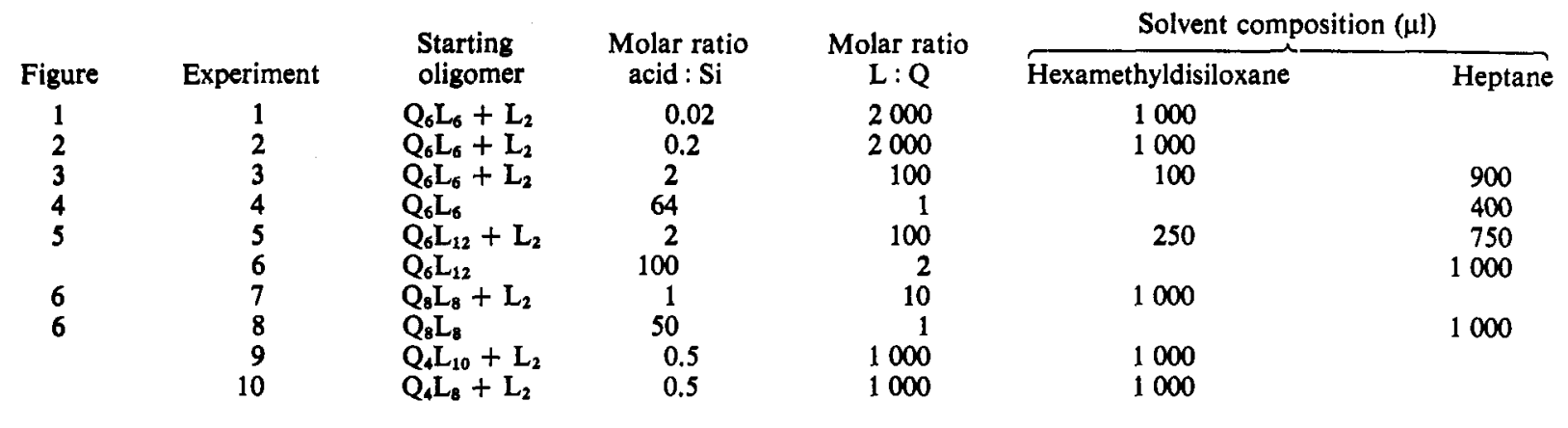

Structures of the compounds involved are given in Table 1. Table 2 gives the experimental parameters. The amount of acid added to the reaction mixture was estimated on the basis of the capacity, $2.9 \mathrm{~mol} \mathrm{l}^{-1}$ of the commercial Amberlyst 15 .

The variations with time of the products of reaction of $\mathrm{Q}_{6} \mathrm{~L}_{6}$ with hexamethyldisiloxane in the presence of Amberlyst
15 are shown in Figures $1-3$. The much faster reaction in Figure 2 compared with that in Figure 1 shows the effect of increased acid content (from Amberlyst 15). In additional experiments performed with trichloroacetic acid and with concentrated sulphuric acid, when the acid contents were identical to those provided by Amberlyst 15 the same products 


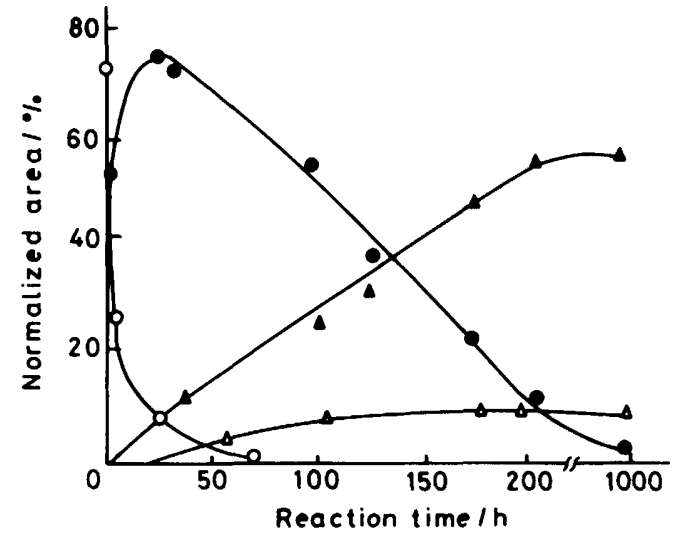

Figure 1. Concentration changes during Amberlyst treatment of a solution of $\mathrm{Q}_{6} \mathrm{~L}_{6}$. Molar ratios: acid : $\mathrm{Si}=0.02 ; \mathrm{L}: \mathrm{Q}=2000: 1$. Species: $\mathrm{Q}_{6} \mathrm{~L}_{6}(\mathrm{O}) ; \mathrm{Q}_{6} \mathrm{~L}_{8}(0) ; \mathrm{Q}_{6} \mathrm{~L}_{10}(\mathrm{I})(\Delta)$ and (II) (A)

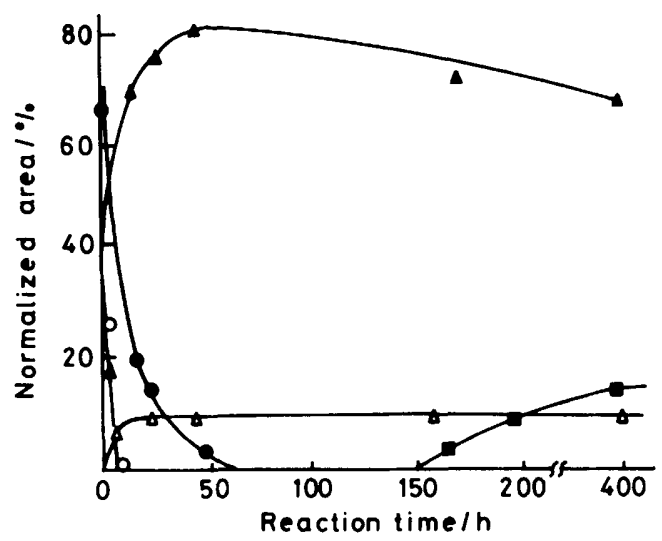

Figure 2. Concentration changes during Amberlyst treatment of a hexamethyldisiloxane solution of $\mathrm{Q}_{6} \mathrm{~L}_{6}$. Molar ratios: acid : $\mathrm{Si}=\mathbf{0 . 2}$; $L: Q=2000: 1$. Species as in Figure 1 except for $Q_{6} L_{12}$ (II) (更)

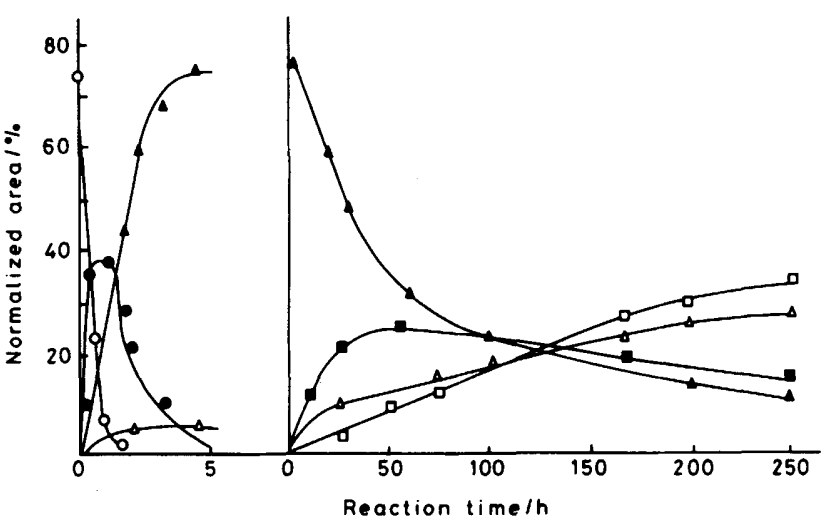

Figure 3. Concentration changes during Amberlyst treatment of a hexamethyldisiloxane solution of $\mathrm{Q}_{6} \mathrm{~L}_{6}$. Molar ratios: acid : $\mathrm{Si}=2$; $L: Q=100: 1$. Species as in Figure 1 except $Q_{6} L_{12}$ (I) (ם) and

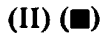

were obtained. Further increase (Figure 3 ) in the acid content coupled with increased hexamethyldisiloxane content results in a similar pattern.

The probable overall reaction sequence is given in Scheme 1. Full arrows represent intermolecular reactions involving the cleavage of one $Q-Q$ bond to give $Q-L$ [type (i) reaction, see<smiles></smiles><smiles></smiles>

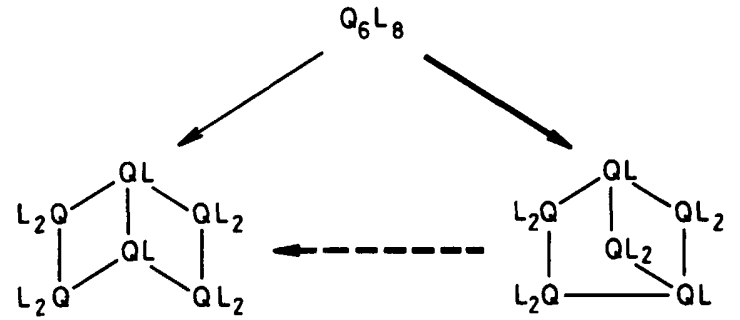

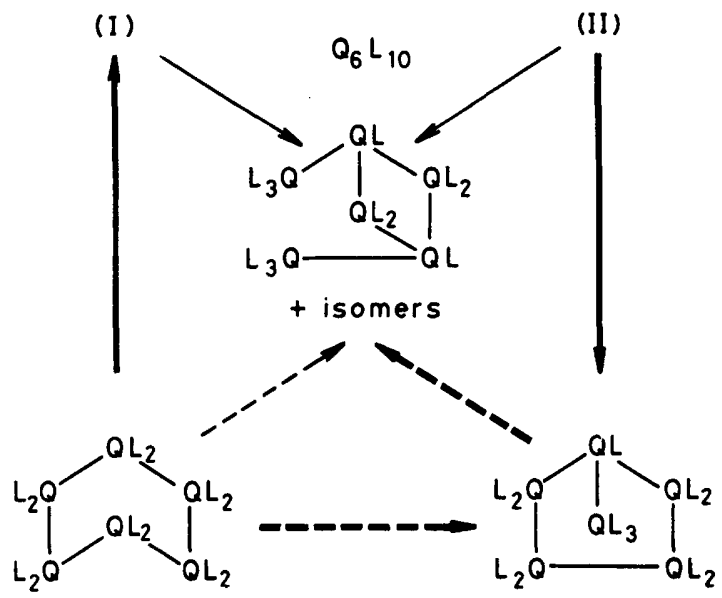

(III)

$$
Q_{6} L_{12}
$$

(II)

Scheme 1. Reaction pathways of the $\mathrm{Q}_{6} \mathrm{~L}_{6}$ and $\mathrm{Q}_{6} \mathrm{~L}_{12}$ (III) transformations

Introduction], i.e. $\mathrm{Q}-\mathrm{Q}+\mathrm{L}-\mathrm{L} \rightarrow 2$ Q-L. Broken arrows represent intramolecular isomerization [type (iii) reaction, see Introduction], i.e. $Q^{1-} Q^{2}+Q^{3}-L \longrightarrow Q^{1}-L+Q^{3}-Q^{2}$. This pathway for $\mathrm{Q}_{6} \mathrm{~L}_{6}$ as depicted in Scheme 1 demonstrates the greater stability of four- compared with three-, five-, and six-membered rings.

In the absence of hexamethyldisiloxane and at high acidity (Figure 4) $\mathrm{Q}_{6} \mathrm{~L}_{6}$ gives $\mathrm{Q}_{6} \mathrm{~L}_{10}, \mathrm{QL}_{4}, \mathrm{Q}_{2} \mathrm{~L}_{6}$, and several minor products, most probably QL siloxanes with $\mathrm{OH}$ groups and $\mathrm{Q}_{6} \mathrm{~L}_{8}$ isomers (cf. refs. 10 and 13).

Figure 5 shows the variation in products with time obtained with $\mathrm{Q}_{6} \mathrm{~L}_{12}$, both in the presence and absence of hexamethyldisiloxane (experiments 5 and 6 ). The reaction pathway is illustrated in Scheme 1 and indicates the preference for the formation of tetrameric rings and the absence of chains. As with $\mathrm{Q}_{6} \mathrm{~L}_{6}$, reaction types (i) and (iii) are evident. The conditions for the reaction with hexamethyldisiloxane are very similar to those used for $\mathrm{Q}_{6} \mathrm{~L}_{6}$ (Figure 3), and it is interesting that the composition of the two reaction mixtures after $250 \mathrm{~h}$ is also similar. 


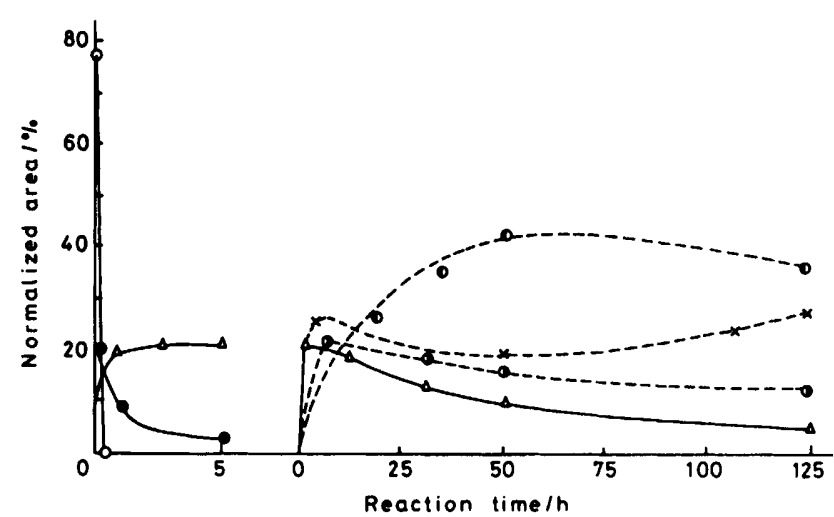

Figure 4. Concentration changes during Amberlyst treatment of a heptane solution of $\mathrm{Q}_{6} \mathrm{~L}_{6}$. Molar ratio: acid : $\mathrm{Si}=64: 1$. Species as in Figure 1 except $\mathrm{QL}_{4}(\mathrm{O})$, unknown $(\times)$, and $\mathrm{Q}_{2} \mathrm{~L}_{6}(\mathbf{O})$

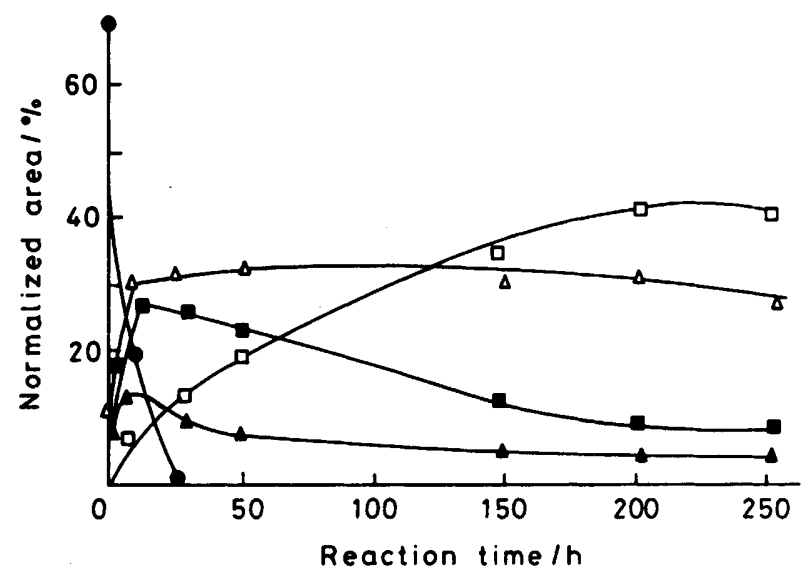

Figure 5. Concentration changes during Amberlyst treatment of a hexamethyldisiloxane-heptane solution of $\mathrm{Q}_{6} \mathrm{~L}_{12}$ (III), the sixmembered ring. Molar ratios as in Figure 3. Species: $Q_{6} L_{10}(I)(\triangle)$

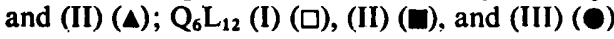

At similar acid concentrations, the compound $\mathrm{Q}_{8} \mathrm{~L}_{8}$ (Figure 6) reacts more slowly in hexamethyldisiloxane solution than does $\mathrm{Q}_{6} \mathrm{~L}_{6}$ (Figure 3), demonstrating the high stability of the double four-membered cage compared to that of the double three-membered cage. Reaction loosens the highly caged structure, while preserving the main characteristic, the tetrameric ring: $\mathrm{Q}_{8} \mathrm{~L}_{8} \rightarrow \mathrm{Q}_{8} \mathrm{~L}_{10}$ (I) $\rightarrow \mathrm{Q}_{8} \mathrm{~L}_{12}$ (I), (II). In heptane solution a second $\mathrm{Q}_{8} \mathrm{~L}_{10}$ isomer designated as (II) is formed as the main product. It probably has the following structure. The species $Y$ has not yet been identified. The<smiles>C1OC23OOC2(O1)OO3</smiles>

excess of $\mathrm{L}$ units in the products obtained in heptane solution originates from other $\mathrm{Q}_{8} \mathrm{~L}_{8}$ molecules. This is supported by the fact that more than $40 \%$ of the ' $Q$ ' units do not appear in the chromatogram of the products after reaction for $200 \mathrm{~h}$.

In hexamethyldisiloxane solutions both $\mathrm{Q}_{4} \mathrm{~L}_{10}$ and $\mathrm{Q}_{4} \mathrm{~L}_{8}$ (experiments 9 and 10) undergo equilibration, resulting in a composition of approximately $98 \% \mathrm{Q}_{4} \mathrm{~L}_{8}$ and $2 \% \mathrm{Q}_{4} \mathrm{~L}_{10}$ after reaction for $200 \mathrm{~h}$. This result considered together with the reactions in Scheme 2 and also equilibration involving $\mathrm{Q}_{8} \mathrm{~L}_{8}$ shows the dual effect of the reactions: highly caged structures

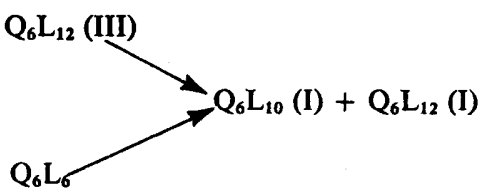

Scheme 2.

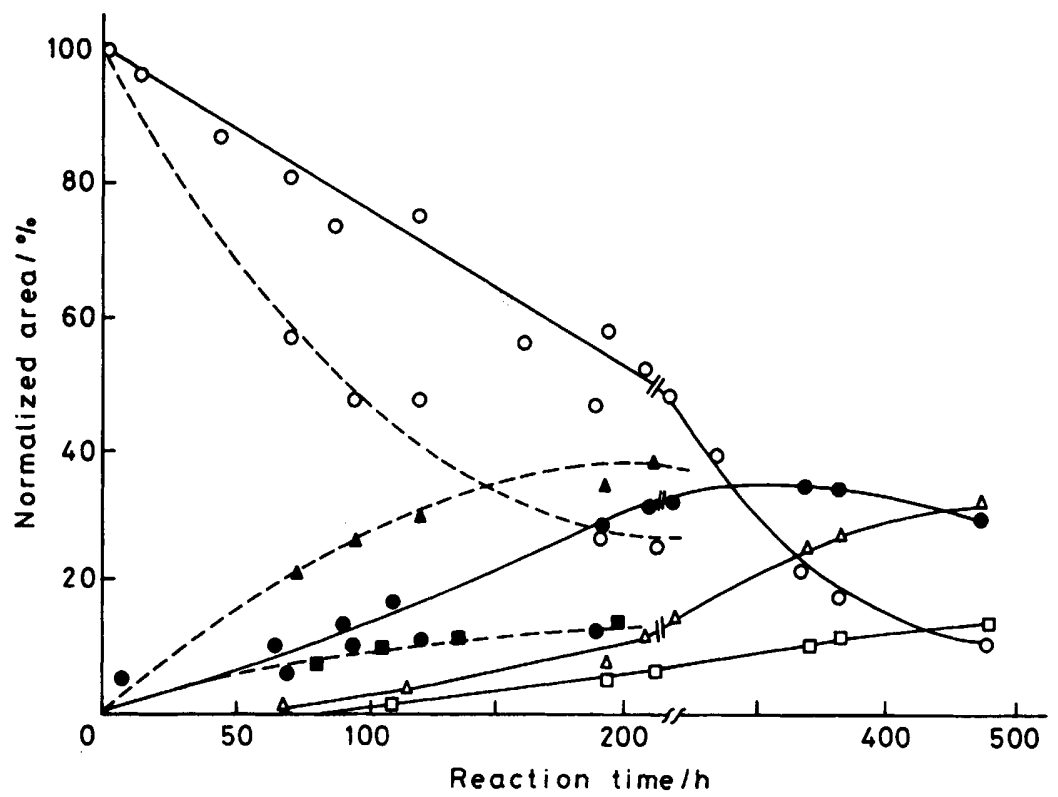

Figure 6. Concentration changes during Amberlyst treatment of $\mathrm{Q}_{8} \mathrm{~L}_{8}$ in hexamethyldisiloxane (- $\longrightarrow$ ) or heptane solution (---). Molar ratios: acid : $\mathrm{Si}=1($

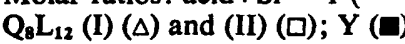
$\rightarrow$ and $50(---) ; \mathrm{L}: \mathrm{Q}=10\left(\longrightarrow\right.$ and $1: 1(--)$. Species: $\mathrm{Q}_{8} \mathrm{~L}_{8}(\mathrm{O}) ; \mathrm{Q}_{8} \mathrm{~L}_{10}(\mathrm{I})(\mathrm{O})$ and (II) (A); 
are loosened, while very loose structures (chains, large rings) become more rigid. As a result, in all instances, siloxane tetramer ring structures are formed.

Amberlyst 15 is a powerful proton donor which acts in a similar way in SiO bond cleavage to trichloroacetic acid and concentrated sulphuric acid. ${ }^{14}$ Its high efficiency is most probably connected with the fact that catalysis of liquid-phase reactions by ion-exchange resins takes place in the immobile pore liquid and therefore may be considered as homogeneous catalysis. ${ }^{15}$ The actual amount of protons available in an $\mathrm{L}_{2}-\mathrm{QL}$ siloxane mixture is considerably lower than that calculated from the amount of acid applied, due to preferential reaction of hexamethyldisiloxane with acid (Scheme 3 ). In the

$$
\mathrm{XH}+\mathrm{Me}_{3} \mathrm{SiOSiMe}_{3} \rightleftharpoons \mathrm{Me}_{3} \mathrm{SiX}+\mathrm{Me}_{3} \mathrm{SiOH}
$$

Scheme 3. $\mathrm{XH}=$ Amberlyst $\mathrm{H}, \mathrm{H}_{2} \mathrm{SO}_{4}$, or $\mathrm{CCl}_{3} \mathrm{CO}_{2} \mathrm{H}$

absence of hexamethyldisiloxane the actual proton concentration equals that supplied by the acid added, and degradative reactions occur to give $\mathrm{QL}_{4}$ - and $\mathrm{OH}$-containing molecular fragments.

\section{Acknowledgements}

The authors thank Dr. Engelhardt for helpful discussion, Mrs. Nemes for carrying out the experiments, drawing the figures, and typing the manuscript, and the third referee for his enormous help in making the paper more understandable.

\section{References}

1 J. Götz and C. R. Masson, J. Chem. Soc. A, 1970, 2683.

2 S. K. Sharma, L. S. Dent Glasser, and C. R. Masson, J. Chem. Soc., Dalton Trans., 1973, 1324.

3 H. P. Calhoun and C. R. Masson, J. Chem. Soc., Dalton Trans., $1978,1342$.

4 H. P. Calhoun and C. R. Masson, J. Chem. Soc., Dalton Trans., $1980,1282$.

5 L. S. Dent Glasser and S. K. Sharma, Eur. Polym. J., 1974, 6, 283.

6 F. D. Tamás, A. K. Sarkar, and D. M. Roy, Hung. J. Ind. Chem., 1977, 5, 115.

7 N. B. Milestone, Cem. Concr. Res., 1977, 7, 345.

8 G. Garzó, D. Hoebbel, Z. J. Ecsery, and K. Ujszászi, J. Chromatogr., 1978, 167, 321.

9 L. S. Dent Glasser and E. E. Lachowski, J. Chem. Soc., Chem. Commun., 1980, 973.

10 G. Garzó, D. Hoebbel, A. Vargha, and T. Székely, J. Chem. Soc., Dalton Trans., 1980, 2068.

11 D. Hoebbel, G. Garzó, G. Engelhardt, R. Ebert, E. Lippmaa, and M. Alla, Z. Anorg. Allg. Chem., 1980, 465, 15.

12 D. Hoebbel and W. Wieker, Z. Anorg. Allg. Chem., 1971, 384, 43.

13 A. Vargha, Ph.D. Thesis (in Hungarian), 1981, Budapest.

$14 \mathrm{~W}$. Noll, 'Chemistry and Technology of 'Silicones,' Academic Press, New York, 1968, pp. 230-235.

15 F. Helfferich, in 'Ion Exchange,' Academic Press, New York, 1962, p. 519.

Received 7th December 1983; Paper 3/2170 